Chapman University

Chapman University Digital Commons

Communication Faculty Articles and Research

School of Communication

5-23-2017

\title{
Coming to the New D.A.R.E.: A Preliminary Test of the Officer-Taught Elementary keepin' it REAL Curriculum
}

\author{
L. Edward Day \\ Chapman University,1day@chapman.edu \\ Michelle Miller-Day \\ Chapman University, millerda@chapman.edu \\ Michael L. Hecht \\ REAL Prevention LLC \\ Desiree Fehmie \\ A.B.E.D.I., Inc.
}

Follow this and additional works at: http://digitalcommons.chapman.edu/comm_articles

Part of the Curriculum and Social Inquiry Commons, Educational Assessment, Evaluation, and $\underline{\text { Research Commons, Elementary Education Commons, and the Substance Abuse and Addiction }}$ Commons

\section{Recommended Citation}

Day, L. E., Miller-Day, M., Hecht, M. L., \& Fehmie, D. (2017). Coming to the new D.A.R.E.: A preliminary test of the officer-taught elementary keepin' it REAL curriculum. Addictive Behaviors, 74, 67-73. https://doi.org/10.1016/j.addbeh.2017.05.025

This Article is brought to you for free and open access by the School of Communication at Chapman University Digital Commons. It has been accepted for inclusion in Communication Faculty Articles and Research by an authorized administrator of Chapman University Digital Commons. For more information, please contact laughtin@chapman.edu. 


\section{Coming to the New D.A.R.E.: A Preliminary Test of the Officer-Taught Elementary keepin' it REAL Curriculum}

\section{Comments}

NOTICE: this is the author's version of a work that was accepted for publication in Addictive Behaviors. Changes resulting from the publishing process, such as peer review, editing, corrections, structural formatting, and other quality control mechanisms may not be reflected in this document. Changes may have been made to this work since it was submitted for publication. A definitive version was subsequently published in Addictive Behaviors, volume 74, in 2017. DOI: 10.1016/j.addbeh.2017.05.025

The Creative Commons license below applies only to this version of the article.

\section{Creative Commons License}

\section{(c) 1 (1) 90}

This work is licensed under a Creative Commons Attribution-Noncommercial-No Derivative Works 4.0 License.

\section{Copyright}

Elsevier 


\section{Accepted Manuscript}

Coming to the new D.A.R.E.: A preliminary test of the officertaught elementary keepin' it REAL curriculum

L. Edward Day, Michelle Miller-Day, Michael L. Hecht, Desiree Fehmie

PII: S0306-4603(17)30202-2

DOI: doi: 10.1016/j.addbeh.2017.05.025

Reference:

AB 5182

To appear in:

Addictive Behaviors

Received date: $\quad 2$ November 2016

Revised date: $\quad 9$ May 2017

Accepted date: $\quad 22$ May 2017

Please cite this article as: L. Edward Day, Michelle Miller-Day, Michael L. Hecht, Desiree Fehmie, Coming to the new D.A.R.E.: A preliminary test of the officer-taught elementary keepin' it REAL curriculum. The address for the corresponding author was captured as affiliation for all authors. Please check if appropriate. Ab(2017), doi: 10.1016/ j.addbeh.2017.05.025

This is a PDF file of an unedited manuscript that has been accepted for publication. As a service to our customers we are providing this early version of the manuscript. The manuscript will undergo copyediting, typesetting, and review of the resulting proof before it is published in its final form. Please note that during the production process errors may be discovered which could affect the content, and all legal disclaimers that apply to the journal pertain. 
Coming to the New D.A.R.E.: A Preliminary Test of the Officer-Taught Elementary keepin' it REAL Curriculum

L. Edward Day ${ }^{\mathrm{a}}$ (corresponding author), Michelle Miller-Day ${ }^{\mathrm{b}}$, Michael L. Hecht $^{\mathrm{c}}$, Desiree Fehmie ${ }^{\mathrm{d}, \mathrm{e}}$

\author{
${ }^{a}$ Department of Sociology \\ Chapman University \\ 1 University Drive \\ Orange, CA 92866 \\ lday@chapman.edu \\ ${ }^{\mathrm{b}}$ Department of Communication Studies \\ Chapman University \\ 1 University Drive \\ Orange, CA 92866 \\ millerda@chapman.edu \\ ${ }^{\mathrm{c}}$ REAL Prevention LLC \\ 765 Long Hill Road \\ Gillette, NJ 07933 \\ michael@ real-prevention.com \\ ${ }^{\mathrm{d}}$ Earl Babbie Research Center \\ Chapman University \\ 1 University Drive \\ Orange, CA 92866 \\ ${ }^{\mathrm{e}}$ Present address: \\ A.B.E.D.I., Inc. \\ 2091 Business Center Drive, Suite 150 \\ Irvine, CA 92612 \\ desireefehmie@gmail.com
}


Coming to the New D.A.R.E.: A Preliminary Test of the Officer-Taught Elementary keepin’ it REAL Curriculum

\begin{abstract}
The present study reports a preliminary evaluation of D.A.R.E.'s new elementary school keepin' it REAL substance abuse prevention program. Given the widespread dissemination of D.A.R.E., this evaluation, even though of short term effects, has important implications for national prevention efforts. The new prevention curriculum teaches social and emotional competencies such as decision making and resistance skills. Social and emotional competencies and other risk factors were examined among students $(\mathrm{N}=943)$ in 26 classrooms, 13 classrooms in the treatment condition $(n=359)$ and 13 classrooms in the control condition $(n=584)$ using a quasi-experimental matched group design. Pretest comparisons of treatment and control groups were completed, along with attrition analyses, and hierarchical logistic and linear regressions were computed to assess the intervention. The results revealed that the intervention produced significant effects on preventative factors such as the likelihood of resisting peer pressure, increased responsible decision making knowledge and decision-making skills, and confidence in being able to explain why they would refuse offers of cigarettes. The results of this study suggest that D.A.R.E.'s elementary keepin' it REAL program has promise as a social and emotional learning (SEL) based prevention program.
\end{abstract}

Keywords: D.A.R.E.; substance use prevention; keepin' it REAL; elementary school

This research was funded by D.A.R.E. America, P.O. Box 512090, Los Angeles, CA 90051-0090 


\section{Coming to the New D.A.R.E.: \\ A Preliminary Test of the Officer-Taught Elementary keepin' it REAL Curriculum}

Substance abuse continues to be a concern with initiation of use typically occurring in early adolescence and prevalence rates of alcohol, tobacco, and marijuana use increasing throughout adolescence (Miech, Johnston, O’Malley, Bachman, \& Schulenberg, 2015), ultimately resulting in potential health and social problems (Reid, Eddy, Fetrow, \& Stoolmiller, 1999). While studies of drug use by children have been limited (Donovan, 2014), early experimentation is clearly a risk factor for later abuse (Jackson, Barnett, Colby \& Rogers, 2015).

Fortunately, significant progress has been made in the prevention field for developing effective substance abuse prevention interventions (Tobler, Roona, Ochshorn, Marshall, Streke, \& Stackpole, 2000) with the most significant progress in programs for middle schools (Ennett et al., 2003). Although evidence suggests that substance use can be prevented or reduced when integrated with efforts to develop students' social and emotional skills in childhood (Belfield et al., 2015; Domitrovich et al., 2017; Zinsser, Weissberg, \& Dusenbury, 2013), relatively few universal substance abuse prevention programs have been developed and evaluated for elementary school students. keepin' it REAL $(k i R)$ is an evidence-based, universal substance abuse prevention program originally developed for middle school students (Hecht, Graham, \& Elek, 2006). This curriculum was adopted by D.A.R.E. America for dissemination at the middle school level and provided the foundation for the creation of a new D.A.R.E. elementary school (EkiR) curriculum. The purpose of this study is to briefly describe the new elementary school-based substance use prevention curriculum and present evidence of its effects.

\section{PREVENTION SCIENCE AND THE EVOLVING D.A.R.E. CURRICULUM}

Rarely in the prevention field has one group occupied as dominant a position as D.A.R.E. America's school-based substance use initiative. From its inception in the early 1980s to its current status, serving almost a million students in the U.S. as well as those in 52 other countries, the success of their curriculum has significant implications for our nation's public health. Unfortunately, scientific evaluations of early D.A.R.E. programs rarely demonstrated efficacy (Ennett, Tobler, Ringwalt, \& 
Flewelling, 1994; US General Accounting Office. 2003). As a result, D.A.R.E. initiated a review of existing, evidence-based programs and in 2008 licensed the keepin' it REAL (kiR) middle school curriculum. keepin' it REAL (kiR) is a culturally grounded (Hecht \& Krieger, 2006), narrative (MillerDay \& Hecht, 2013), multicultural middle school curriculum (Colby, Hecht, Miller-Day, Krieger, Syverstsen, Graham, \& Pettigrew, 2013). It is based on narratives collected from hundreds of youth across the country describing their experiences with drug offers and other problematic situations that require a sophisticated set of communication and relationship management skills (Colby et al., 2013). The curriculum is highly interactive and engaging (Colby et al., 2013) and previous group randomized trials demonstrated it reduces substance use as much as 14 months after the intervention ends (Hecht et al., 2006). After successful adaptation for officer delivery, the new D.A.R.E. middle school curriculum was implemented in 2009.

A similar review convinced D.A.R.E. to work with the kiR developers to create an elementary curriculum that articulates with the middle school lessons, leading to the development of the elementary keepin' it REAL (EkiR) curriculum which was implemented in 2012. The prevention strategy guiding the development of EkiR was social emotional learning theory (SEL) (Durlak et al., 2015)). Social and emotional learning is the process through which social-emotional competence develops. Through SEL, children and youth acquire and effectively apply the knowledge, attitudes, and skills necessary to understand and manage emotions, set and achieve positive goals, feel and show empathy for others, establish and maintain positive relationships, and make responsible decisions (Durlak et al., 2015). SEL programming is based on the understanding that improving proximal skills such as social and emotional competencies are critical to being a good student, citizen, and worker; and many distal risky behaviors (e.g., drug use, violence, bullying, and dropout) can be prevented or reduced by integrated efforts to develop students' social and emotional skills (Domitrovich, Durlak, Staley, \& Weissberg, 2017). This approach has a strong empirical base with a growing body of research linking SEL to improved prosocial behavior and academic achievement and reductions in aggression and substance use (Belfield, 2015; Domitrovich et al, 2017; Weissberg et al, 2015). 
Given the prominence of D.A.R.E. in the prevention community, the effectiveness of this new elementary curriculum is an immediate concern. This study was designed to pilot procedures for a larger study and provide an evaluation of short term effects of the program. Consistent with previous research (Donovan, 2014; Miech et al., 2015), substance use among this elementary school sample was, as anticipated, negligible (at pretest, last 30-day use of alcohol and tobacco were 3.8\% and $0.5 \%$, respectively) and thus this first short-term evaluation focused on competencies, attitudes, and cognitions rather than actual drug use. We emphasized decision making, measuring both knowledge and skills, because the curriculum focuses very heavily on this competency with four lessons largely devoted to, and five other lessons practicing, these skills. We also measure recall of the basic concepts, called definitional knowledge below. Finally, we examined 2 proximal outcomes, interest in smoking and attitudes toward police, the former because it is a predictor of future smoking and the latter as an evaluation of D.A.R.E. as a community policing strategy. The following hypotheses were tested:

H1: EkiR will increase definitional knowledge, decision-making knowledge, decision-making skill, refusal confidence, self-control, communication skills, and positive attitudes toward police.

H2: $\quad$ EkiR will decrease susceptibility to peer pressure and interest in smoking.

\section{METHODS}

\subsection{Sample}

Methods and procedures used in this study were approved by the Institutional Review Board of a western university. A quasi-experimental pretest-posttest, matched group design was implemented during spring 2014 in $266^{\text {th }}$ grade classrooms from 7 elementary schools $(N=943)$. While a group randomized trial would have been ideal, random assignment to D.A.R.E. is problematic due to the very nature of the D.A.R.E. structure. While often seen as a monolithic organization, D.A.R.E. is a manifestation of community policing. Only local police and local schools can decide to teach D.A.R.E. and this partnership is central to the D.A.R.E. system. D.A.R.E. America provides a national curriculum and sets the training standards for new and continuing officers. As a result, without a large budget to support 
incentives, a matched group design was determined to be the most efficient design for this preliminary study.

\subsection{Procedures}

Five treatment condition schools were recruited among those teaching D.A.R.E.'s EkiR in spring 2014 by a police department in the southwestern United States. After school district approval, principals and teachers were recruited from 13 sixth grade classrooms. The total number of students in the treatment condition was $359($ male $=163)($ female $=196)$. Three D.A.R.E. officers from the participating police department also consented to participate.

Control schools were recruited by matching SES, geographic proximity to the treatment schools, and not having access to any officer-led prevention curricula. District prevention activities for the control schools during the study period were limited to hosting a red ribbon week. Again, after school district and principals' approval, 13 sixth grade classrooms agreed to participate as control schools. The number of students in the control condition was $584($ male $=302)($ female $=282)$.

Teachers provided parents with study information sheets, contact information for research staff, and a request for consent for their child's participation. If parents wished for their child to opt out of participation, they were instructed to contact research staff. If a parent did not opt their child out of participation, then the student was given the option to assent. Two students were opted out of the project by their parents, one in the treatment group and one in the control group, and they were provided alternative activities. All remaining students assented.

Unique student identification codes were assigned and the list linking student codes to students was secured by the study team and destroyed at the end of the study. Teachers in both conditions directed their students to the study website, provided the students with a tear off sheet that had the student's name and unique identification number, and had the students enter the code into the survey. The tear sheets with student names were then destroyed.

Students in both conditions completed identical pre-test and post-test online surveys in school computer labs under the direction of their teachers. Research staff cleaned data entry errors involving 
student identification codes by referring to class rosters. All partic ipants who completed both the presurvey and post-survey were included in data analysis.

\subsection{Intervention}

D.A.R.E.'s The Elementary keepin' it REAL (EkiR) consists of ten 45-minute lessons teaching the five core SEL skills: self-awareness and management, decision- making, understanding and helping others, relationship and communication skills, and handling responsibilities. Each lesson begins with a summary of the previous lesson with transition to an animated video presenting a narrative about a challenging situation in which the lesson topic is addressed (e.g., managing emotions). The officer then leads a discussion resulting in the definition of a skill followed by application of concepts and skills to problem situations in their student workbook. Application is followed by small group/dyadic/or individual skill practice, with a concluding summary discussion, assignment of homework for further application and practice, and a concluding live action video summarizing core ideas from the lesson and introducing the topic for the next lesson. The homework becomes the basis for the next lesson's summary. To further reinforce the lesson material, there is also a comic book titled REAL Adventures depicting the challenging situations and resolutions from the lessons.

\subsection{Measures}

Demographic risk variables included gender (female $=0$, male $=1$ ), whether or not the student received free lunches or breakfasts at school (a proxy measure of social class, no=0, yes=1), and selfreported grades as a measure of academic achievement (higher values reflect higher grades in academic subjects). Race and ethnicity were not available variables for this analysis due to concern about this variable at the school district level.

2.4.1. Definitional knowledge. Definitional knowledge of the following concepts was assessed: evaluating your own decisions, confident communication, interpersonal resistance, and empathy. For each concept, a definition was provided and respondents were asked to choose the appropriate concept from three choices. The items were scored so that 1 reflects a correct answer and 0 reflects an incorrect one. 
2.4.2 Social and emotional le arning competencies. Drawing from CASEL's social and emotional learning domains (CASEL, 2015), a number of competencies were measured. The larger domains included: responsible decision making, self-management, social awareness, and relationship skills.

Decision-making skills. Decision-making skills were measured with two scales, decision-making knowledge and decision-making skills and application. The decision-making knowledge scale (Mincemoyer \& Perkins, 2003) consisted of eleven items assessing how respondents define and evaluate problems. Students responded to the items on a 3 -point scale $(1=$ almost never, $2=$ sometimes, $3=$ almost always). Cronbach's alpha was .74. The decision-making skills and application scale consisted of five items assessing how students would respond to a scenario where an older cousin acting as babysitter invites friends over without permission. The measure was created for this study based on the skills taught in the program. Students responded to the items such as "How likely is it that you would stop and define the problem facing you?" on a 4-point scale ( 1 = Not at all likely, $2=$ Unlikely, $3=$ Likely, $4=$ Very likely). This scale was selected because it aligns specifically with the problem-focused method of decision-making taught in the EkiR lessons. Cronbach's alpha was .76.

Self-Management. Two aspects of self-management were assessed, refusal confidence and selfcontrol. Refusal confidence was measured by assessing their ability to apply the four strategies identified in previous research: refuse, explain, avoid, and leave (Colby et al., 2013; Miller et al., 2000). Students were presented with a scenario and asked how confident they were that they could use each skill. Since the internal consistency of this scale was not optimal for this study population $(\alpha=.60)$, the four items were examined individually. Self-control was measured by a six-item subscale of the Assessment of Liability and Exposure to Substance Use and Antisocial Behavior for children scale (Ridenour, 2003; Ridenour, Clark, \& Cottler, 2009). Participants responded on a 3-point scale $(1=$ almost never, $2=$ sometimes, 3 = almost always). Cronbach's alpha was .77. 
Relationship skills. Two relationship skills were assessed, communication skills and susceptibility to peer pressure. Communication skills were assessed by 4 single items developed specifically for this study to assess four different communication skills promoted in the curriculum. The items mirrored those developed by Parker \& Asher (1993). Participants responded on a 3-point scale $(1=$ almost never, 2 = sometimes, 3 =almost always). Susceptibility to peer pressure was measured by two separate items extracted from the Assessment of Liability and Exposure to Substance Use and Antisocial Behavior for Children scale (Ridenour, 2003; Ridenour, Clark, \& Cottler, 2009). Responses were on a 3-point scale of ( 1 = not okay, 2 = okay, 3 = definitely okay). These two items were analyzed separately.

2.4.3. Intent to smoke. Intent to smoke tobacco was assessed since intent is a strong predictor of smoking behavior (Tucker, Elickson, \& Klein, 2002) and smoking itself is one of the stronger predictors for future use of other substances for elementary age youth (Torabi, Bailey, \& Majd-Jabbari,1993). This was measured with a single item from Ridenour (2003). Participants were asked "Would you like to try smoking tobacco some day?" and responded on a 3 -point scale $(1=$ yes, $2=$ maybe, $3=$ no).

2.4.4. Attitudes toward police. Attitudes toward police were measured by four items from the Perceptions of Police scale (Brandt \& Marcus, 2000). Participants responded on a 3-point scale of $(1=$ not true, $2=$ sort of true, 3 = very true). All items were coded so that higher scores reflect more favorable attitudes toward police. Cronbach's alpha was .51. Since the internal consistency of this scale was poor for this study population, the four items were examined individually.

\subsection{Analys is Plan}

Analyses presented below include pretest comparisons of treatment and control groups, attrition analyses, and hierarchical logistic and linear regressions to test the study hypotheses. The nonrandom design required comparisons of pretest differences between conditions before moving on to the main analyses

\section{RESULTS}

\subsection{Pre test Comparis ons of Treatment and Control Groups.}


Pretest differences between treatment and control groups were examined. Only statistically significant pretest differences are reported here. The treatment group students reported more knowledge or skill for the following: defining evaluation of your own decisions, defining confident communication, favorable skills in applying effective decision-making strategies, self-control, the communication skills of maintaining eye contact and examining body language, and the ability to explain why they would refuse an offer of a cigarette. The treatment group was also significantly more likely to report that officers are usually friendly.

Pretest differences may indicate that the treatment group was on a more prosocial trajectory prior to exposure to the D.A.R.E. curriculum. These pretest differences were controlled statistically in the final analyses by including pretest measures in the regression equations as control variables.

\subsection{Attrition.}

Possible attrition bias was assessed by examining predictor variables for the entire sample. We observed significant differences between stayers and leavers on the measures for socio-economic status (the free meals at school item) and academic achievement (self-reported grades). Leavers, but only those in the control condition, were more likely to report receiving free lunch or breakfast at school and to report lower grades. The overall conclusion is that attrition was not a significant threat to validity. If there is attrition bias, in this situation, it would bias results toward the null hypothesis.

\subsection{Intervention Effects}

The effects of the D.A.R.E. program were assessed with a series of hierarchical logistic and linear regressions with the treatment variable examined after the effects of gender, SES (measured as participation in the free lunch or breakfast program), academic achievement (measured as self-reported grades) and the time one measures of dependent variables had been accounted for in a prior step.

3.3.1. Effects on Knowledge. Table 1 presents hierarchical logistic regression results for knowledge of concepts presented in the curriculum. For all four concepts, students in the D.A.R.E. treatment group increased their knowledge significantly more than did control students after controlling for pretest 
knowledge. These findings suggest that students are understanding and retaining, at least in the short term, the content of D.A.R.E. lessons.

[Table 1 about here]

3.3.2. Effects on SEL Competencies. Results for analyses of SEL competencies are presented in Tables 2, 3, and 4. In Table 2, analyses of decision-making scales showed significant effects in the predicted direction for both measures. Controlling for pretest differences, students in the D.A.R.E. condition reported significantly greater decision-making knowledge and reported a significantly greater likelihood of applying decision-making skills.

[Table 2 about here]

Table 3 presents results for the SEL domain of self-management (refusal confidence and selfcontrol). Controlling for the pre-test differences, D.A.R.E. students were significantly more confident that they could offer an explanation for not accepting an offer of a cigarette, the most common strategy used by youth in previous research (Miller-Day et al., 2006). There were no significant differences observed in their confidence to use the other strategies and no effects on self-control.

[Table 3 about here]

Table 4 presents results for the relationship skills domain, The D.A.R.E. curriculum showed significant positive effects on two of the four measures of communication skill (use of eye contact and assessment of the other's body language). No significant effects were observed for the perspective taking or assertiveness measures. There is some evidence that the program improved resistance to peer pressure. Treatment students were significantly more likely to resist the pressure to attend a movie instead of studying. However, there was no difference between groups in willingness to accept a cigarette. This may be due to the fact that almost none of the students smoked, making offers infrequent and resistance unnecessary. 
[Table 4 about here]

\subsubsection{Effects on intent to s moke and attitudes toward police. Table 5 indicates the} intervention did not significantly affect intent to smoke $(\mathrm{p}=.08)$. Again, there was little variation to explain. Of the 761 valid responses to the item, only 9 students reported that they wanted to try smoking, 23 reported maybe, and 729 reported no.

[Table 5 about here]

Regarding attitudes toward police, Table 5 shows that significantly more students in the treatment group report that police would help people in need. There were no significant differences for the other three items. The overall results is consistent with previous studies of perceptions of police delivering prevention programs, which show that early adolescents tend to have relatively stable and favorable views of police compared with older cohorts (Stewart, Morris, \& Weir, 2014).

\section{CONCLUSIONS}

This study provides a preliminary and short-term evaluation of D.A.R.E.'s EkiR, a program based on social and emotional learning theoretical principles. A quasi-experimental matched group design in which matched D.A.R.E. and non-D.A.R.E. schools are compared provides a less rigorous test than a randomized controlled design, but also approximates real-world conditions associated with implementation of the D.A.R.E. program. Given the important reach of this program and the need for an evaluation, the current study provides some promising findings.

EkiR had clear and positive effects on the knowledge and application of many of the targeted basic social emotional learning skills (e.g., responsible decision making, self-monitoring, and relationship skills). Statistically significant effects demonstrate that treatment students reported a greater likelihood of resisting peer pressure on some measures, and reported more confidence in being able to explain why 
they would refuse offers of cigarettes. D.A.R.E. students also scored higher on measures of knowledge of concepts directly related to the curriculum, demonstrating that lesson content is being learned and retained.

On the other hand, a number of non-significant effects were observed. For resistance, no effects were found for avoiding offers and leaving when offered. Avoiding tends to be a more sophisticated communication strategy found more frequently among older youth (Hecht, Alberts, \& Miller-Rassulo, 1992) while leaving is difficult for younger children who have less mobility control. It may also be that there were no differences in resistance to smoking offers due to their infrequency. Finally, and probably most troubling, was the lack of effects on self-control and assertiveness. Self-control, in particular, is a central SEL competency for this age group (Rimm-Kaufman et al., 2015) and D.A.R.E. may need to provide greater stress on this concept in future training. On the other hand, as both skills are found to emerge as youth age, future longitudinal studies may capture these effects.

A number of significant limitations are acknowledged. Only self-report data are examined and there were a number of measures with moderate to low reliability which may have contributed to some of the non-significant findings. Social norms, which are often key to long term effects, and actual substance use could not be examined due to ceiling effects (almost all had negative norms and very few reported smoking). Finally, students represented a limited demographic (e.g., SES, geography) reducing our ability to generalize. The curriculum is intended for elementary school youth and should have similar effects on 5th grade students. Yet, due to potential developmental differences, it is unclear if the curriculum will have similar effects on 6th grade students in middle school settings.

Overall, the results of this study suggest that interest in using substances can be affected in elementary students using a social and emotional competence enhancement approach and show promise for the effectiveness of the D.A.R.E. elementary school curriculum (EkiR). While further evaluation of the program across a range of conditions and types of students is warranted, the current analyses provide outcomes comparable to those obtained by some programs listed on websites such as NREPP and other successful SEL programs (Durlak et al. 2015). As predicted by SEL theory, improved social and 
emotional competencies become important child assets with positive consequences for development and long-term outcomes such as substance use (Rimm-Kaufman \& Hulleman, 2015). 


\section{References}

Belfield, C., Bowden, B., Klapp, A., Levin, H., Shand, R., \& Zander, S. (2015). The economic value of social and emotional learning. Report from the Center for Benefit-Cost Studies in Education Teachers College, Columbia University.

Brandt, D.E. \& Markus, K. A. (2000). Adolescent attitudes toward the police: A new generation. Journal of Police and Criminal Psychology, 15(1):10-16.

CASEL (2015). CASEL Guide: Effective social and emotional learning programs. Chicago, IL: Collaborative for Academic, Social, and Emotional Learning.

Colby, M., Hecht, M.L., Miller-Day, M., Krieger, J.R., Syverstsen, A.K., Graham, J.W., \& Pettigrew, J. (2013). Adapting School-based Substance Use Prevention Curriculum through Cultural Grounding: An Exemplar of Adaptation Processes for Rural Schools. American Journal of Community Psychology, 51, 190-205. DOI: 10.1007/s10464-012-9524-8

Domitrovich, C. E., Durlak, J. A., Staley, K. C., \& Weissberg, R. P. (2017). Social- Emotional Competence: An essential factor for promoting positive adjustment and reducing risk in school children. Child Development, 88(2), 408-416.

Donovan, J. E. (2014). The burden of alcohol use: focus on children and preadolescents. Alcohol Research: Current Reviews, 35(2), 186.

Durlak, J.A., Domitrovich, C.E., Weissberg, R.P., \& Gullotta, T.P. (eds) (2015). Handbook of social and emotional learning. NY: Guilford Press.

Ennett, S. T., Ringwalt, C. L., Thorne, J., Rohrbach, L. A., Vincus, A., Simons-Rudolph, A., \& Jones, S. (2003). A comparison of current practice in school-based substance use prevention programs with meta-analysis findings. Prevention Science, 4(1), 1-14. 
Ennett, S. T., Tobler, N. S., Ringwalt, C. L., \& Flewelling, R. L. (1994). How effective is drug abuse resistance education? A meta-analysis of Project DARE outcome evaluations. American Journal of Public Health, 84(9), 1394-1401.

Hecht, M.L., Alberts, J.K., \& Miller-Rassulo, M. (1992). Resistance to drug offers among college students. International Journal of the Addictions, 27, 995-1017.

Hecht, M.L., Colby, M., \& Miller-Day, M. (2010). The Dissemination of keepin' it REAL through D.A.R.E. America: A lesson in disseminating health messages. Health Communication, 25, 585586.

Hecht, M.L., \& Krieger, J.K. (2006). The principle of cultural grounding in school-based substance use prevention: The Drug Resistance Strategies Project. Journal of Language and Social Psychology, 25,301-319. doi: $10.1177 / 0261927 X 06289476$

Hecht, M.L., Graham, J.W. \& Elek, E. (2006). The Drug Resistance Strategies intervention: Program effects on substance use. Health Communication, 20, 267-276. PMID17137418

Jackson, K. M., Barnett, N. P., Colby, S. M., \& Rogers, M. L. (2015). The prospective association between sipping alcohol by the sixth grade and later substance use. Journal of Studies on Alcohol and Drugs.

Miech, R. A., Johnston, L. D., O’Malley, P. M., Bachman, J. G., \& Schulenberg, J. E. (2015). Monitoring the Future national survey results on drug use, 1975-2014: Volume I, Secondary school students. Ann Arbor: Institute for Social Research, The University of Michigan.

Miller, M.A., Alberts, J.K., Hecht, M.L., Krizek, R.L., \& Trost, M. (2000). Adolescent relationships and drug abuse. NY: Erlbaum Publications. 
Miller, T., \& Hendrie, D. (2008). Substance Abuse Prevention Dollars and Cents: A Cost-Benefit Analysis, DHHS Pub. No. (SMA) 07-4298. Rockville, MD: Center for Substance Abuse Prevention, Substance Abuse and Mental Health Services Administration, 2008.

Miller-Day, M., \& Hecht, M.L. (2013). Narrative means to preventative ends: A Narrative engagement framework for designing prevention interventions. Health Communication, 28, 657-670. doi:10.1080/10410236.2012.762861

Mincemoyer, C. C., \& Perkins, D. F. (2003). Assessing decision-making skills of youth. The Forumfor Family and Consumer Issues, 8(1), 1-9.

Parker, J. G., \& Asher, S. R. (1993). Friendship and friendship quality in middle childhood: Links with peer group acceptance and feelings of loneliness and social dissatisfaction. Developmental Psychology, 29, 611-621.

Pettigrew, J., Graham, J. W., Miller-Day, M., Hecht, M. L., Krieger, J. L., Shin, Y (2015). Adherence and delivery quality: Implementation quality and outcomes of 7th grade keepin' it REAL program. Prevention Science, 16 (1), 90-99. doi: 10.1007/s11121-014-0459-1

Reid, J. B., Eddy, J. M., Fetrow, R. A., \& Stoolmiller, M. (1999). Description and immediate impacts of a preventive intervention for conduct problems. American Journal of Community Psychology, 27(4), 483-518.

Ridenour, T. A. (2003). Assessment of Liability and Exposure to Substance use and Antisocial behavior@(ALEXSA@), CORE Measures. Allison Park, PA.

Ridenour, T. A., Clark, D. B., \& Cottler, L. B. (2009). The illustration-based Assessment of Liability and EXposure to Substance use and Antisocial behavior@ for children. The American Journal of Drug and Alcohol Abuse, 35(4), 242-252. 
Rimm-Kaufman, S., \& Hulleman, C. (2015). SEL in elementary school settings: Identifying mechanisms that matter. In J.A. Durlak, C.E. Domitrovich, R.P. Weissberg, \& T.P. Gullotta, (eds). Handbook of social and emotional learning (p. 151-166). NY: Guilford Press.

Stewart, D. M., Morris, R. G., and Weir, H. 2014. Youth perceptions of the police: Identifying trajectories. Youth Violence and Juvenile Justice, 12 (1), 22-39. doi: 10.1177/1541204013480369.Tobler, N. S., Roona, M. R., Ochshorn, P., Marshall, D. G., Streke, A. V., \& Stackpole, K. M. (2000). School-based adolescent drug prevention programs: 1998 meta-analysis. Journal of Primary Prevention, 20(4), 275-336.

Torabi, M. R., Bailey, W. J., \& Majd-Jabbari, M. (1993). Cigarette smoking as a predictor of alcohol and other drug use by children and adolescents: evidence of the "gateway drug effect". Journal of School Health, 63(7), 302-306.

Tucker, J., Ellickson, P., \& Klein, D. (2002). Smoking cessation during the transition from adolescence to young adulthood. Nicotine and Tobacco Research 4(3), 321-332.

US General Accounting Office, 2003. Youth illicit drug use prevention: DARE long-term evaluations and federal efforts to identify effective programs. GAO-03-172R. Washington, DC: US General Accounting Office. http://www.gao.gov/new.items/d03172r.pdf

Washington State Institute for Public Policy (2014). Benefit cost technical documentation. Olympia, WA.

Zinsser, K. M., Weissberg, R. P., \& Dusenbury, L. (2013). Aligning preschool through high school social and emotional learning standards: A critical and doable next step. Chicago: Collaborative for Academic, Social, and Emotional Learning. 
Table 1: Hierarchical Logistic Regression of Time 2 D.A.R.E. Definitional Knowledge Items on Treatment

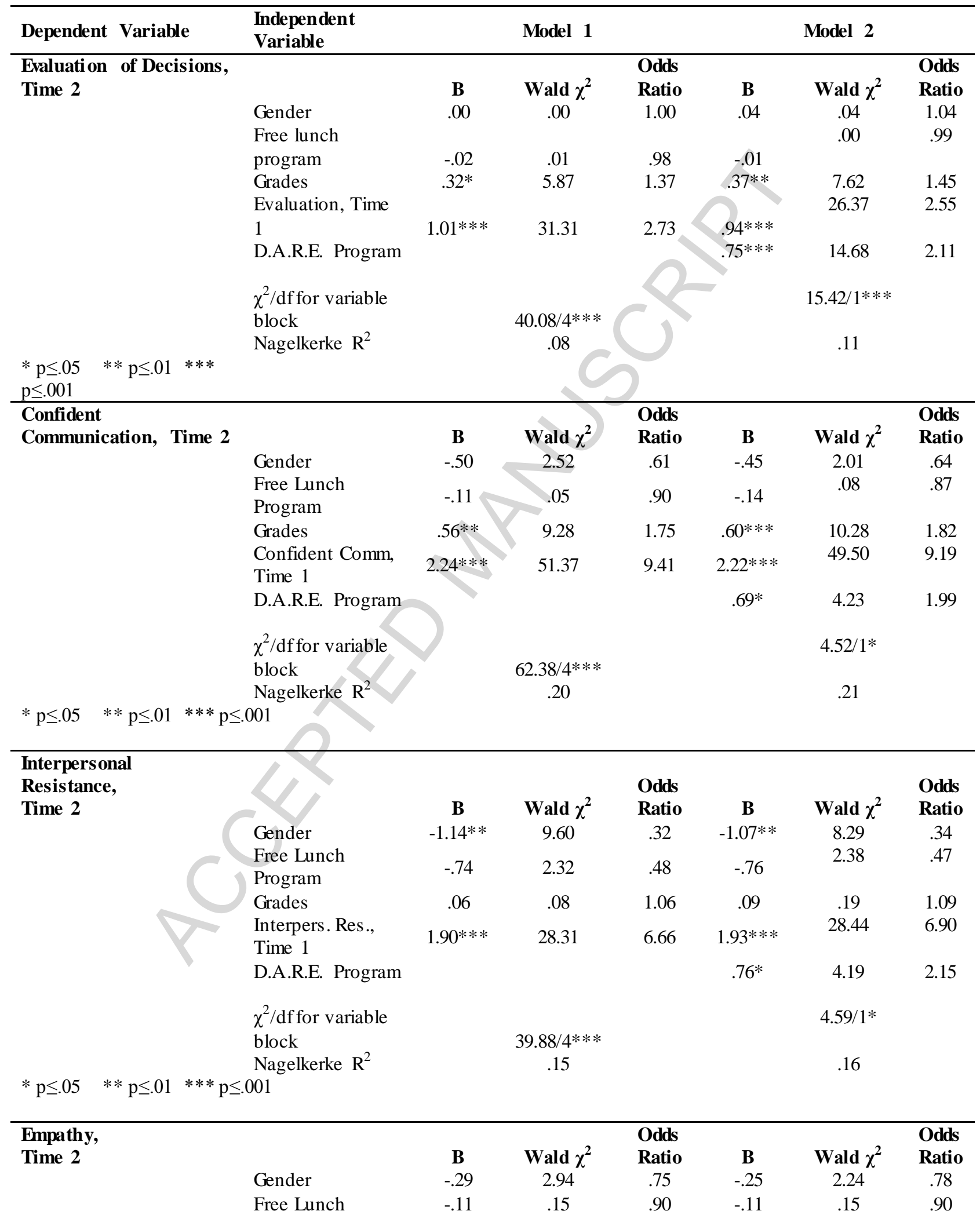




\begin{tabular}{|c|c|c|c|c|c|c|c|c|}
\hline & & $\begin{array}{l}\text { Program } \\
\text { Grades }\end{array}$ & .11 & .87 & 1.12 & .17 & 1.89 & 1.19 \\
\hline & & Empathy, Time 1 & 1.27 & 58.70 & 3.56 & $1.23 * * *$ & 53.09 & 3.41 \\
\hline & & D.A.R.E. Program & & & & $.81 * * *$ & 20.37 & 2.25 \\
\hline & & $\begin{array}{l}\chi^{2} / \text { df for variable } \\
\text { block } \\
\text { Nagelkerke } R^{2}\end{array}$ & & $\begin{array}{c}65.83 / 4 * * * \\
.12\end{array}$ & & & $\begin{array}{c}21.19 / 1 * * * \\
.16\end{array}$ & \\
\hline $\begin{array}{l}* \mathrm{p} \leq .05 \\
\mathrm{p} \leq .001\end{array}$ & $* * \mathrm{p} \leq .01 \quad * * *$ & & & & & & & \\
\hline
\end{tabular}


Table 2: Hierarchical Regression of SEL Competency Measures on Treatment: Decision-Making Knowledge and Decision-Making Skills and Application

\begin{tabular}{|c|c|c|c|c|c|}
\hline $\begin{array}{l}\text { Dependent Variable } \\
\text { Decision-Making Knowledge, } \\
\text { Time } 2\end{array}$ & \multirow[b]{2}{*}{$\begin{array}{l}\text { Independent Variable } \\
\\
\text { Gender } \\
\text { Free lunch program } \\
\text { Grades } \\
\text { Decision Knowledge, Time } 1 \\
\text { D.A.R.E. Program }\end{array}$} & & \multicolumn{3}{|c|}{ Model 2} \\
\hline $\begin{array}{l}\text { Decision-Making Knowledge, } \\
\text { Time } 2\end{array}$ & & $\begin{array}{l}\mathbf{b} \\
-.02 \\
.02 \\
.04 * \\
.60 * * *\end{array}$ & $\begin{array}{l}\boldsymbol{\beta} \\
-.03 \\
.01 \\
.08 \\
.53\end{array}$ & $\begin{array}{l}\mathbf{b} \\
-.02 \\
.02 \\
.05 * * \\
.59 * * * \\
.07 * *\end{array}$ & $\begin{array}{l}\boldsymbol{\beta} \\
-.03 \\
.02 \\
.09 \\
.52 \\
.10\end{array}$ \\
\hline $\begin{array}{l}\mathrm{R}^{2} \\
\mathrm{~F} \text { for change in } \mathrm{R}^{2} \\
* \mathrm{p} \leq .05 \quad * * \mathrm{p} \leq .01 \quad * * * \mathrm{p} \leq .001\end{array}$ & & $7.72 * * *$ & & $\begin{array}{c}.32 \\
9.82 * *\end{array}$ & \\
\hline $\begin{array}{l}\text { Decision-Making Skills and } \\
\text { Application, Time } 2\end{array}$ & $\begin{array}{l}\text { Gender } \\
\text { Free Lunch Program } \\
\text { Grades } \\
\text { Decision Skills, Time } 1 \\
\text { D.A.R.E. Program }\end{array}$ & $\begin{array}{l}-.03 \\
.02 \\
.09 * * * \\
.58 * * *\end{array}$ & $\begin{array}{l}\boldsymbol{\beta} \\
-.03 \\
.01 \\
.11 \\
.52\end{array}$ & $\begin{array}{l}\mathbf{b} \\
-.03 \\
.02 \\
.10 * * * \\
.57 * * * \\
.10 * *\end{array}$ & $\begin{array}{l}\boldsymbol{\beta} \\
-.02 \\
.01 \\
.12 \\
.51 \\
.10\end{array}$ \\
\hline $\begin{array}{l}\mathrm{R}^{2} \\
\mathrm{~F} \text { for change in } \mathrm{R}^{2} \\
* \mathrm{p} \leq .05 \quad * * \mathrm{p} \leq .01 \quad * * * \mathrm{p} \leq .001\end{array}$ & 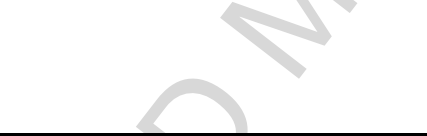 & $\begin{array}{c}.30 \\
74.81 * * *\end{array}$ & & $\begin{array}{l}.31 \\
8.02 * *\end{array}$ & \\
\hline
\end{tabular}


Table 3: Hierarchical Regression of SEL Self-Management Measures on Treatment: Confidence in Refusal Skills and Self-Control over Anti-Social Behavior

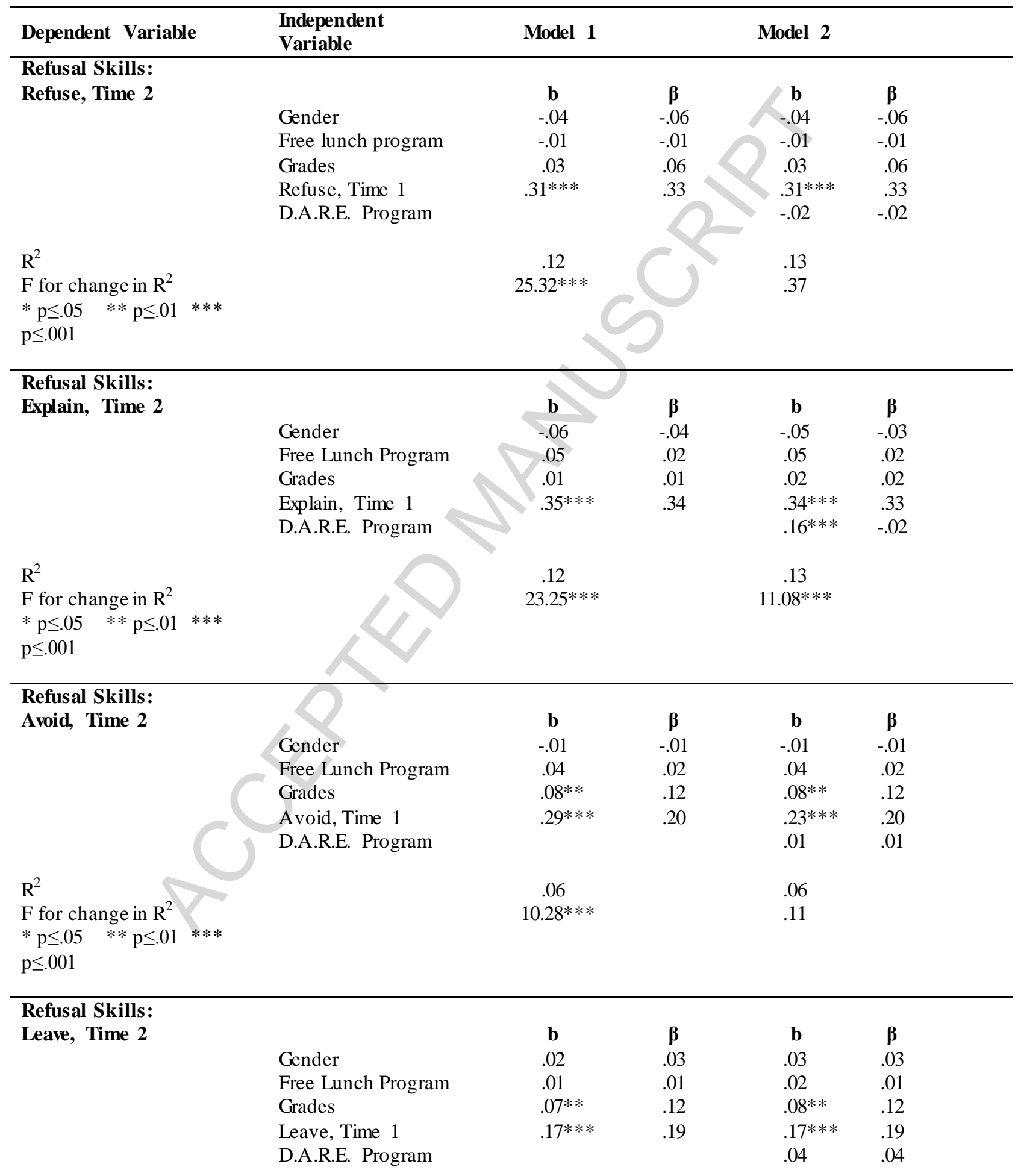


$\mathrm{R}^{2}$

$F$ for change in $R^{2}$

$* \mathrm{p} \leq .05 \quad * * \mathrm{p} \leq .01 \quad * * *$ $\mathrm{p} \leq .001$
$.05 \quad .05$

$9.05 * * * \quad 1.26$

\begin{tabular}{llcccc}
\hline Self-Control, Time 2 & & $\mathbf{b}$ & $\boldsymbol{\beta}$ & $\mathbf{b}$ & $\boldsymbol{\beta}$ \\
& Gender & -.06 & -.08 & -.06 & -.09 \\
& Free Lunch Program & .01 & .01 & .01 & .01 \\
& Grades & .05 & .09 & .05 & .09 \\
& Self-Control, Time 1 & .66 & .64 & .66 & .64 \\
& D.A.R.E. Program & & & .01 & .01 \\
$\mathrm{R}^{2}$ & & .47 & & .47 & \\
$\mathrm{~F}$ for change in $\mathrm{R}^{2}$ & & $156.80 * * *$ & & .17 & \\
$* \mathrm{p} \leq .05 \quad * * \mathrm{p} \leq .01 * * *$ & & & & & \\
$\mathrm{p} \leq .001$ & & & & \\
& & & & & \\
\hline
\end{tabular}


Table 4: Hierarchical Regression of SEL Measures on Treatment: Communication Skills and Susceptibility to Peer Pressure

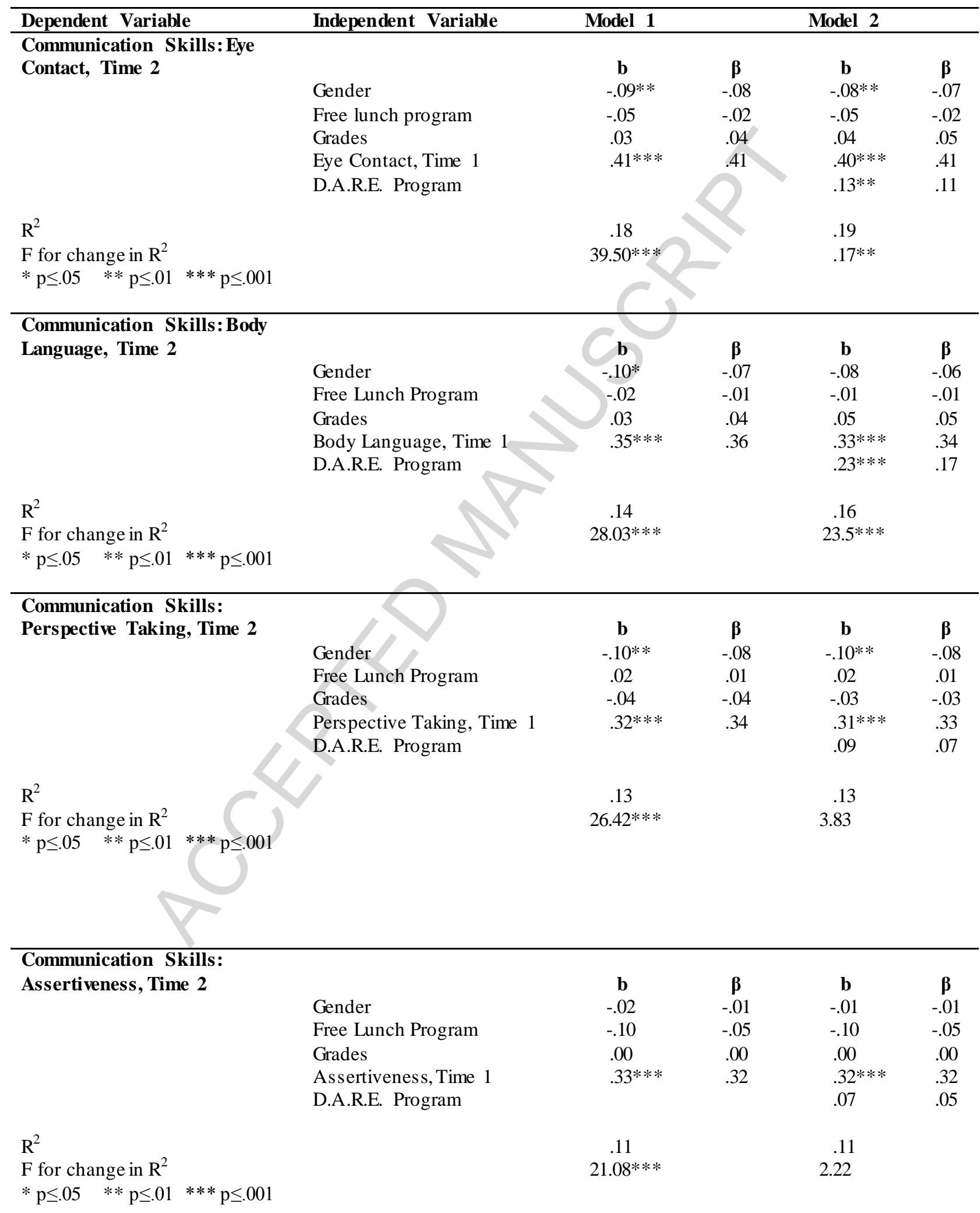




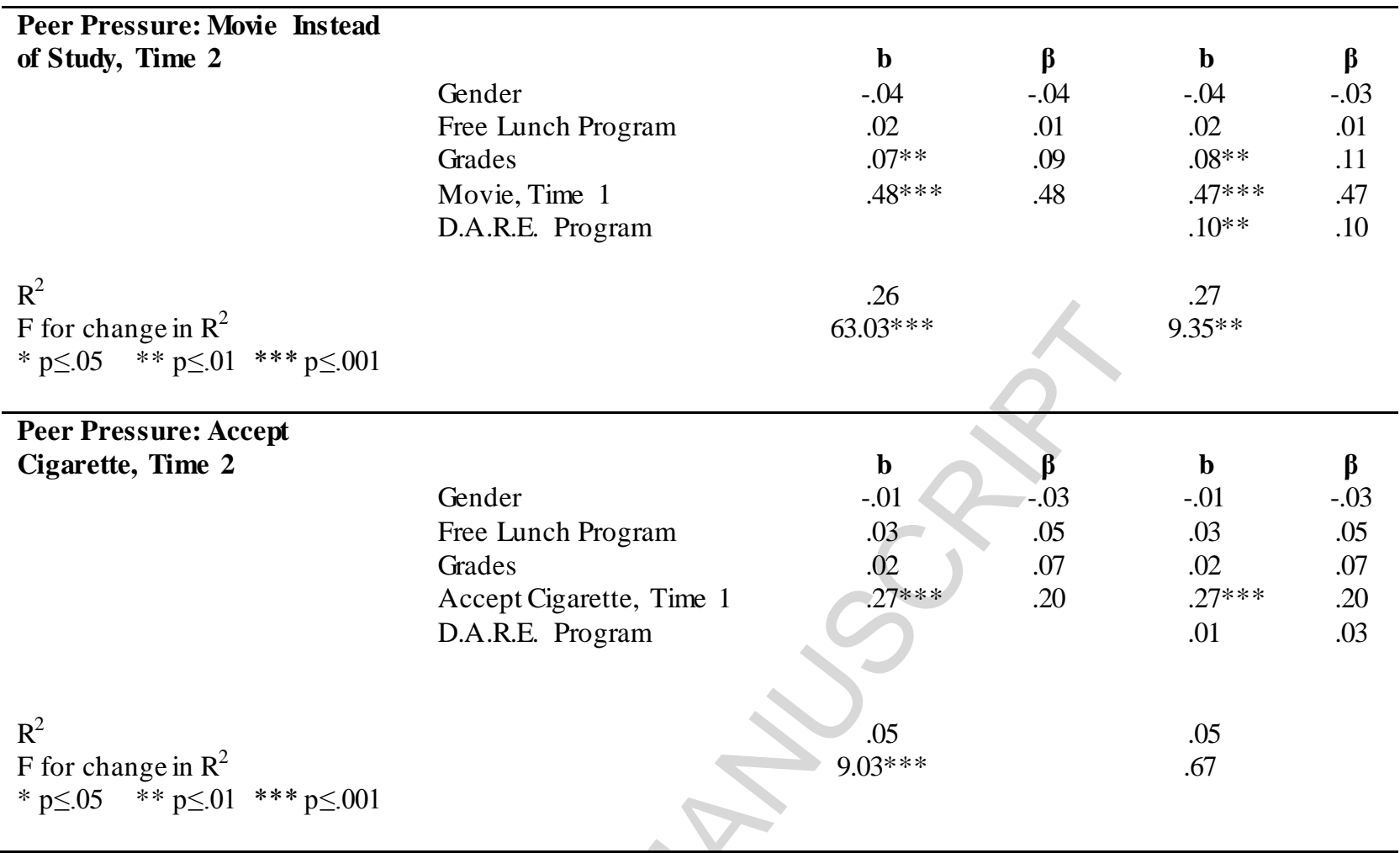

Table 5: Hierarchical Regression of Intent to Smoke and Attitudes toward Police on Treatment

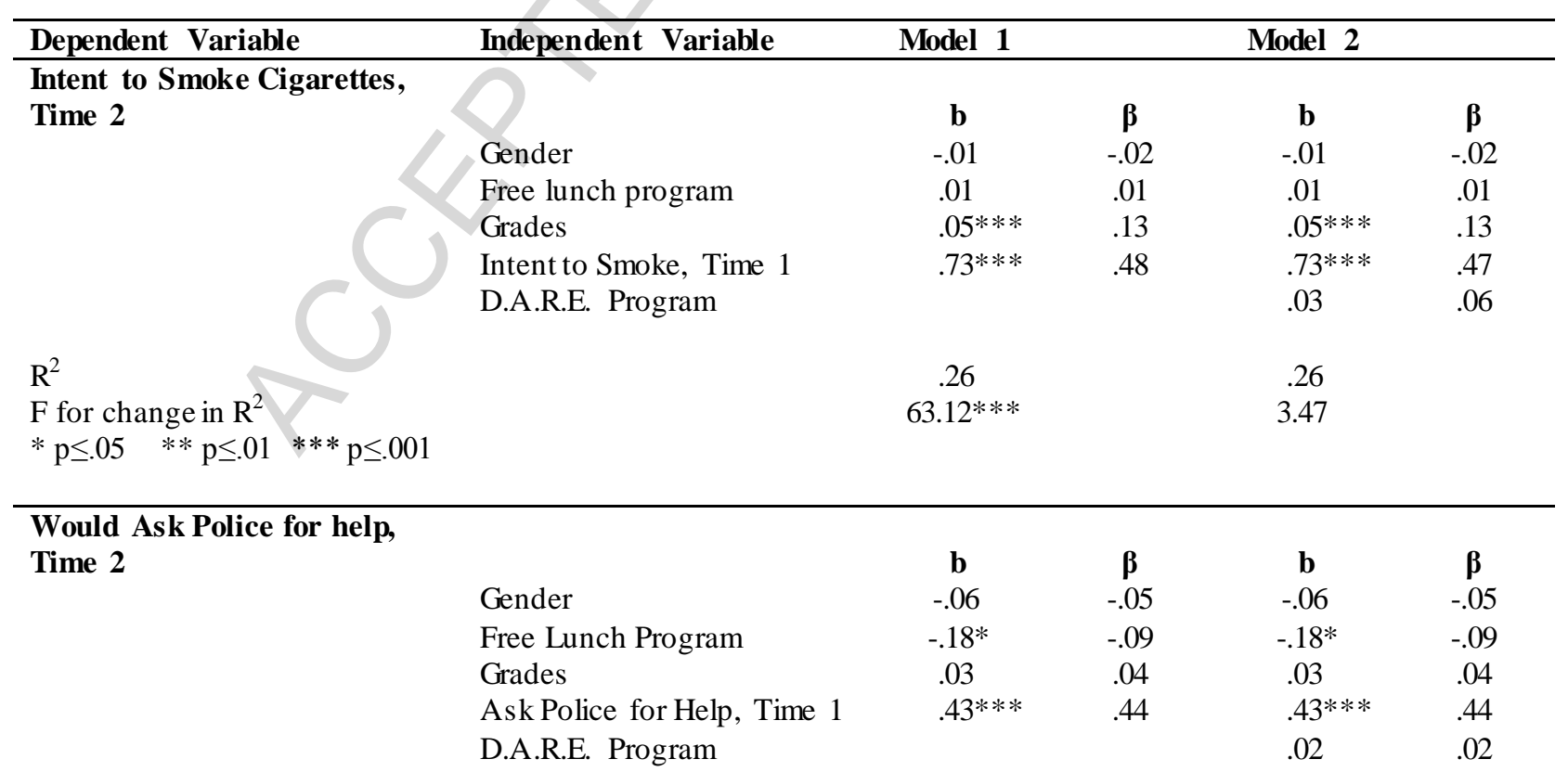


$\mathrm{R}^{2}$

.21

.21

$\mathrm{F}$ for change in $\mathrm{R}^{2}$

$47.44 * * *$

.33

$* \mathrm{p} \leq .05 \quad * * \mathrm{p} \leq .01 * * * \mathrm{p} \leq .001$

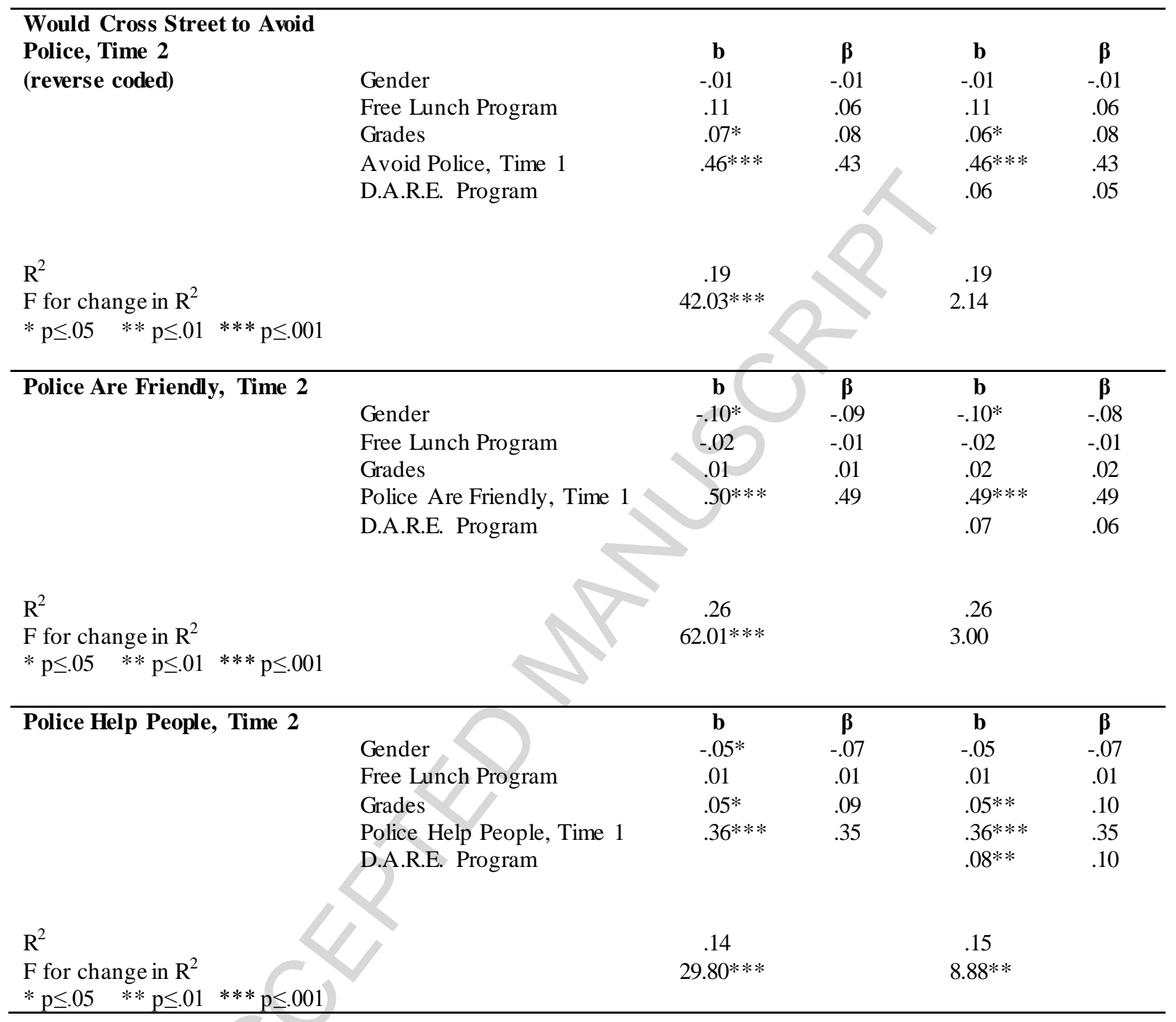




\section{Role of Funding Sources}

Funding for this research was provided by D.A.R.E. America. D.A.R.E. America had no role in the study design, collection, analysis or interpretation of the data, writing the manuscript, or the decision to submit the paper for publication.

\section{Contributors}

All authors participated in the study design and preparation of the manuscript. Miller-Day and Day developed the survey instrument. Fehmie directed data collection and served as the primary contact person for study participants. Day conducted the analysis. All authors approve of the final manuscript. Conflict of Interest

Three of the authors have a financial conflict of interest. Miller-Day and Hecht developed the curriculum and own the intellectual property through their company, Real Prevention LLC. The curriculum is licensed to D.A.R.E. America by Real Prevention. Both Drs. Miller-Day and Hecht benefit financially from the arrangement. Dr. Day benefits financially through marriage. D.A.R.E. America funded this study through a contract granted to the Earl Babbie Research Center at Chapman University. 


\section{Highlights}

- The first evaluation of the new D.A.R.E. America elementary school program is presented.

- Students who were exposed to the D.A.R.E. kiR program rank higher in social and emotional skills that lay the foundation for resistance skills.

- D.A.R.E. students scored significantly higher in measures of knowledge of concepts directly related to the D.A.R.E. curriculum (e.g., confident communication and empathy), indicating that the program effectively transmits its core ideas. 